\title{
MAMMALS
}

\section{GRAY SQUIRRELS AND MAGPIES}

KEITH BARR, 40 Richardson Crescent, Regina, Saskatchewan. S4S 4J3

I have spent about an hour a day, on average, in Wascana Park for the last three years. I have been told that there are Gray Squirrels in the park and they have been there for several years. I had not seen one till early this spring when my wife spotted one on the ground going from tree to tree, followed by a magpie. It appears that the magpie was as interested in the squirrel as I was.

Five weeks later we see a Gray Squirrel again. This time three mag- pies are following the squirrel as he goes from tree to tree. Just a minute! The magpies are not following, they are chasing the squirrel and being very boisterous about it. Now this squirrel is not a country bumpkin just in town for the day. No siree! This guy has street sense. Even being harassed by the magpies, the squirrel stops about 20 feet from a road and lets several cars go by before he makes a dash across the road to thicker bushes. The magpies are right behind. The squirrel stops a

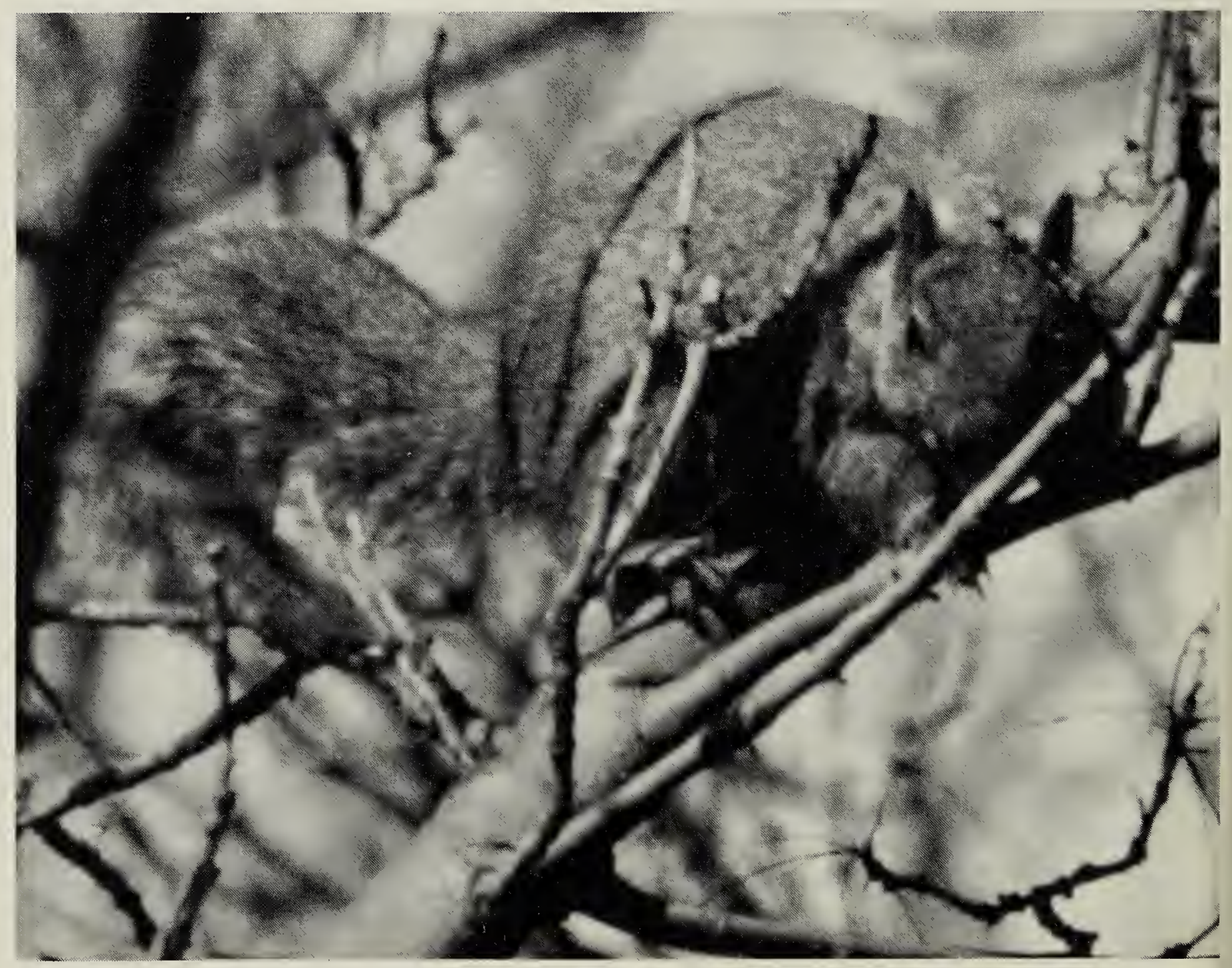


